\title{
Soluble P2X7 receptor is elevated in the plasma of COVID-19 patients and correlates with disease severity
}

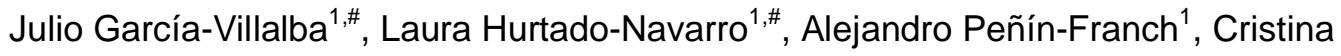

Molina-López ${ }^{1}$, Laura Martínez-Alarcón ${ }^{1}$, Diego Angosto-Bazarra ${ }^{1}$, Alberto Baroja-

$$
\text { Mazo }^{1} \text {, Pablo Pelegrín }{ }^{1,2}
$$

${ }^{1}$ Biomedical Research Institute of Murcia (IMIB-Arrixaca), University Clinical Hospital Virgen Arrixaca, 30120 Murcia, Spain.

${ }^{2}$ Department of Biochemistry and Molecular Biology B and Immunology, Faculty of Medicine, University of Murcia, 30120 Murcia, Spain.

"Equal contribution.

Corresponding author: Dr. Pablo Pelegrín. Edificio LAIB 4로 Planta, Instituto Murciano de Investigación Biosanitaria (IMIB-Arrixaca). Carretera Buenavista s/n. 30120 EI Palmar, Murcia, Spain. Phone: +34 868885038; e-mail: pablo.pelegrin@imib.es

RUNNING TITTLE: P2X7 levels in COVID-19.

KEYWORDS: COVID-19, SARS-CoV-2, inflammation, P2X7, purinergic receptors, piroptosis. 


\begin{abstract}
Inflammation is a tightly coordinated response against bacterial and viral infections, triggered by the production of pro-inflammatory cytokines. SARS-CoV-2 infection induces COVID-19 disease, characterized with an inflammatory response mediated by the activation of the NLRP3 inflammasome resulting with the production of IL-1 $\beta$ and IL-18 together with pyroptotic cell death. Severe inflammation in the lungs of SARSCoV-2 infected individuals associate with pneumonia, hypoxia and acute respiratory distress syndrome, being the cause of the deaths associated to COVID-19. Here we found that together with the increase of IL-6, IL-18 and the IL-1 receptor antagonist in the plasma of COVID-19 patients, the purinergic P2X7 receptor was also elevated. Increase of COVID-19 disease severity and C-reactive protein concentration positively correlated with increased concentration of the $\mathrm{P} 2 \mathrm{X} 7$ receptor in the plasma, but not with IL-18 cytokine. P2X7 receptor was found in the supernatant of human peripheral blood mononuclear cells after inflammasome activation, suggesting that $\mathrm{P} 2 \mathrm{X} 7$ receptor determination in the plasma could be a novel biomarker of COVID-19 disease severity.
\end{abstract}




\section{Introduction}

Coronavirus disease 2019 (COVID-19) develops upon infection with the severe acute respiratory syndrome coronavirus 2 (SARS-CoV-2), and according to the Johns Hopkins University COVID-19 dashboard as of 10 February 2022 there have been over 400 million infections and 5.7 million deaths worldwide (coronavirus.jhu.edu/map.html). SARS-CoV-2 primarily infects cells of the respiratory tract and cause different degrees of symptomatology, being the severe cases developing pneumonia with hypoxia and acute respiratory distress syndrome (ARDS) [1]. Lungs of COVID-19 patients with ARDS show a considerable infiltration of neutrophils and monocytes with an increase of the concentration of several pro-inflammatory cytokines in the blood [1-3]. The nucleotide-binding oligomerization domain, leucine rich repeat and pyrin domain containing-protein 3 (NLRP3) inflammasome controls the release of bioactive interleukin (IL)-1 $\beta$ and IL-18 cytokines by activating caspase-1 and inducing pyroptosis cell death $[4,5]$. Caspase-1 also cleaves gasdermin D (GSDMD) that induces pores in the plasma membrane allowing the release of $\mathrm{IL}-1 \beta$ and $\mathrm{IL}-18[4,6,7]$. The NLRP3 inflammasome is activated by different signals, including triggering of the P2X7 receptor by extracellular ATP, the phagocytosis of particulate matter or the infection with specific virus and bacteria [8-10]. The SARS-CoV-2 virus induces the activation of NLRP3 [11-15], and this inflammasome has been implicated in the production of proinflammatory cytokines during severe cases of COVID-19, being associated to the severity of ARDS [12,16,17]. A clinical trial in COVID-19 patients with anakinra (the recombinant IL-1 receptor antagonist) has found a decrease in the severity of the respiratory failure, restoring the inflammatory response [18]. Mechanistically, the SARS-CoV-2 viroporin encoded by ORF3a triggers cellular $\mathrm{K}^{+}$efflux and activates NLRP3 [19], being a decrease of intracellular $\mathrm{K}^{+}$a well-known activator of the NLRP3 inflammasome [20]. Also, the SARS-CoV-2 N protein and the ORF8 encoded protein are able to interact with NLRP3 and induce its activation [21,22]. During SARS-CoV-2 infection there is a reprogramming of the host macrophages, making them able to be 
primed for the NLRP3 inflammasome by the virus spike (S) protein [23]. On the other hand, the SARS-CoV-2 virus also block the inflammasome pathway at different levels, for example, the envelope (E) protein impairs NLRP3 priming [24], the non-structural proteins 1 and 13 suppress the activation of the NLRP3 inflammasome [25] and the N protein cleaves GSDMD within the N-terminal lytic domain inactivating pyroptosis [26]. Therefore, there is a fine balance of the NLRP3 inflammasome activation during SARS-CoV-2 infection.

In this study we have found that during active COVID-19 disease there is an elevation of plasma concentration of $\mathrm{IL}-18$ and the $\mathrm{IL}-1$ receptor antagonist (IL-1Ra), as well as a soluble form of the purinergic P2X7 receptor. IL-1Ra and P2X7 receptor both increased with the severity of COVID-19 symptoms, but only P2X7 receptor correlated with CRP concentration in the plasma of COVID-19 patients. 


\section{Results}

A total of 208 plasma samples collected between September 2020 and March 2021 from individuals with confirmed SARS-CoV-2 infection and different degree of COVID19 disease gravity were recruited in the Region of Murcia in the southeast of Spain (Table 1). A control cohort of 69 individuals from the same geographical area without SARS-CoV-2 infection and without inflammatory or infection symptoms were collected during 2016-2019 (pre-COVID 19 pandemic) (Table 1). The acute phase protein Creactive protein (CRP) was elevated above standard threshold in the plasma of patients infected with SARS-CoV-2 (Fig. 1A). However, procalcitonin (PCT) appeared only elevated in some COVID-19 patients (Fig. 1A), whereas ferritin was increased in most of COVID-19 patients (Fig. 1A). As expected, IL-6 cytokine was also elevated in the plasma of patients infected with SARS-CoV-2 when compared to control healthy individuals (Fig. 1B), and in agreement with previous publications [3,13], IL-15, IL-1RA and IL-18 were also elevated (Fig. 1B). However, other cytokines or chemokines, as CCL2/MCP-1 and IL-2, that have been described increased in COVID-19 patients [3] were not elevated in the plasma of our cohort of SARS-CoV-2 infected patients when compared to healthy individuals (Fig. 1C).

The presence of the soluble $\mathrm{P} 2 \mathrm{X} 7$ receptor was significantly increased in the plasma of SARS-CoV-2 patients when compared to healthy individuals (Fig. 1D). However, other markers of pyroptosis (HMGB1, ASC and GSDMD) were not elevated in the plasma of SARS-CoV-2 infected patients when compared to healthy individuals (Fig. 1D). Of note, only $27.5 \%$ of healthy individuals and in $25 \%$ of COVID-19 patients, presented a positive detection of GSDMD in the plasma, suggesting that in the majority of individuals, and irrespectively of the infection, GSDMD was under the detection threshold. Similarly, HMGB1 was only detected in $58 \%$ of healthy donors and in $74 \%$ of COVID-19 patients. For all the other identified proteins, their detection was very similar among healthy donors and COVID-19 patients, and with a detection range above $80 \%$ of the analysed samples. 
The concentration of CRP in the plasma of COVID-19 patients significantly increased according to the categories of illness severity (Fig. 2A). Disease severity categories were defined according the clinical spectrum of SARS-CoV-2 infection covering mild, moderate and severe/critical illness as described in the latest guide of the National Institutes of Health COVID-19 treatment guidelines. A total of 41 mild, 128 moderate and 39 severe COVID-19 cases were identified (Table 1). However, PCT appeared only significantly elevated in the severe COVID-19 group (Fig. 2A) and ferritin was increased in mild and severe groups when compared to the group of mild manifestations of the disease (Fig. 2A).

P2X7 receptor and IL-1RA were significantly increased in the plasma of COVID-19 patients across all severity groups when compared to healthy donors (Fig. 2B). IL-6 and IL-15 were not increased in mild COVID-19 patients, but was significantly elevated in moderate and severe cases (Fig. 2C). Only in moderate COVID-19 patients IL-18 was significantly increased (Fig. 2C). The increase of P2X7 receptor in the plasma of COVID-19 patients was independent of the age, since we found an increase in all age groups, but only significative in the 60 to 80 years group (Fig. 2D).

The amount of soluble P2X7 receptor, as well as the concentration of the cytokines IL6 and IL-15, positively correlated with the amount of CRP in the plasma (Fig. 3A,B). The positive correlation between P2X7 receptor and CRP was improved within the moderate and severe COVID-19 groups, but in contrast IL-6 and IL-15 correlation with CRP was decreased in these groups (Fig. 3C). Neither IL-1RA nor IL-18 cytokines correlated with CRP when all COVID-19 patients were analysed (Fig. 3A,B), or when the moderate and severe groups were separated (not shown). While CRP also positively correlated with ferritin concentration (Fig. 3D), ferritin had a weaker correlation with P2X7 receptor and no correlation with IL-18 (Fig. 3D). However, the soluble P2X7 receptor was positively correlating with the different cytokines analysed, presenting the best correlation with the increase of IL-18 in the plasma (Fig. 3E). This suggests that soluble P2X7 receptor increase with the severity of COVID-19 illness. 
P2X7 receptor release has been observed in human macrophages after treatment with the semi-selective P2X7 receptor agonist benzoyl ATP [27], and therefore we asked if ATP treatment of human peripheral blood mononuclear cells (PBMCs) would also result in the shedding of $\mathrm{P} 2 \mathrm{X} 7$ receptor. Our results showed that ATP was able to increase the concentration of P2X7 receptor found in the supernatant of LPS-treated PBMCs (Fig. 4). This LPS and ATP treatment also induces the activation of the NLRP3 inflammasome [8], as was evidenced by the release of IL-1 $\beta$ (Fig. 4). Furthermore, activation of the Pyrin inflammasome also resulted in a release of P2X7 receptor and IL-1 (Fig. 4), supporting the notion that both P2X7 receptor and inflammasomedependent caspase-1 activation could be linked to the shedding of P2X7 receptor from human blood cells. 


\section{Discussion}

COVID-19 severe symptoms are related to an exacerbated inflammatory response mediated by the production of several pro-inflammatory cytokines $[1,3]$. In the present study, we corroborate in a cohort of COVID-19 patients from the southeast of Spain an elevated concentration of the cytokines IL-6, IL-15, IL-18 and IL-1RA. Together with these cytokines, we found that the purinergic receptor P2X7 is also increased in the plasma of symptomatic COVID-19 patients, being higher with disease severity and correlating with the levels of the acute phase protein CRP and different cytokines. The activation of the P2X7 receptor leads to the activation of the NLRP3 inflammasome and the release of IL-1 $\beta$ and IL-18 cytokines $[8,10]$, together also with the shedding of P2X7 receptor in microparticles [27]. Here we show that human peripheral blood mononuclear cells release P2X7 receptor upon ATP treatment. This suggests that potential NLRP3 inflammasome activation and subsequent pyroptosis could be partially responsible for the release of microparticles loaded with $\mathrm{P} 2 \mathrm{X} 7$ receptor, as the ESCRT machinery induce shedding of GSDMD-damaged membranes $[4,28]$. In support, we also describe that the activation of the Pyrin inflammasome and subsequent pyroptosis, that is independent on the P2X7 receptor, also leads to the release of P2X7 receptor. Increased concentrations of soluble P2X7 receptor in the blood has been described positively correlating with the concentration of CRP $[27,29]$, being soluble $\mathrm{P} 2 \mathrm{X} 7$ receptor elevated during infection and sepsis [27,30], as well as during temporal lobe epilepsy [29]. Our results agree with these previous studies, and describe that the SARS-CoV-2 infection also leads to an increase of the soluble P2X7 receptor in the blood, positively correlating with CRP concentration. In fact, recent studies have reported the activation of the inflammasome during SARS-CoV-2 infection and relate it to the severity of COVID-19 disease [15]. These evidences suggest that the detection of P2X7 receptor could be a promising novel blood-biomarker for inflammatory processes, supporting the diagnosis and severity of COVID-19 disease. In addition, targeting P2X7 receptor with drug-like pharmacological antagonists has been 
suggested as a promising strategy to treat severe-inflammatory and neurological complications of COVID-19 patients [31,32].

The concentration of IL- 6 has been clinically used to evaluate the severity of COVID-19 disease [3]. Also, IL-6 has been used as a therapeutic target, and IL-6 blocking antibodies have been widely used to treat COVID-19 patients [33]. IL-6 is a cytokine produced downstream IL-1 $\beta$, meanwhile IL-1RA is a cytokine blocking IL-1 signalling as it binds to the type I IL-1 receptor and impair IL-1 to trigger its receptor [34]. Even in sepsis or autoinflammatory syndromes, usually treated with anti-IL-1 therapy, the blood concentration of $\mathrm{IL}-1 \beta$ are very low and usually not detected $[30,35]$. Despite the evidences of inflammasome activation during COVID-19, IL-1 $\beta$ is not detected in the blood samples of COVID-19 patients [13]. Detection of IL-1RA is therefore a systemic indicative of IL-1 $\beta$ production, and our study, in agreement with a previous study [13] demonstrates an important increase of IL-1RA in the blood of COVID-19 patients, suggesting a production of IL-1 $1 \beta$.

While the axes IL-1 $\beta /$ IL-6 links to CRP production in bacterial infections, IL-18 production links to transferrin in viral infection [36]. However, in the plasma of SARSCoV-2 infected patients we found an elevation of both axes, IL-6/CRP and IL18/transferrin, but while IL-6 positively correlated with CRP, IL-18 failed to correlated with transferrin in COVID-19 patients. P2X7 correlated with CRP, supporting previous studies [27,29], but not with transferrin, denoting that the shedding of P2X7 receptor is somehow related to the IL-6/CRP inflammatory programme in both bacterial [37] and SARS-CoV-2 viral (this study) infections.

In conclusion, our study shows that the soluble $\mathrm{P} 2 \mathrm{X} 7$ receptor concentration increases in the plasma of COVID-19 and positively correlates with disease severity and CRP protein concentration. This correlation was not found for IL-18 or other cytokines, but they increase in the plasma of COVID-19 patients. Furthermore, P2X7 receptor was 
bioRxiv preprint doi: https://doi.org/10.1101/2022.03.04.483019; this version posted March 7, 2022. The copyright holder for this preprint (which was not certified by peer review) is the author/funder, who has granted bioRxiv a license to display the preprint in perpetuity. It is made available under aCC-BY-NC-ND 4.0 International license.

released from human PBMCs upon inflammasome activation, suggesting that P2X7 receptor could be a novel blood biomarker for COVID-19 severity. 


\section{Material and methods}

Human samples

Samples and data from patients included in this study, who gave written informed consent, were collected, processed and provided by the Biobanco en Red de la Región de Murcia, BIOBANC-MUR, registered on the Registro Nacional de Biobancos with registration number B.0000859, and were processed following standard operating procedures with appropriate approval of the Ethical Committees (2021-5-10-HCUVA). A total of 208 recovered individuals previously tested RT-PCR-positive, positive serology, and/or rapid antigen test for SARS-CoV-2 were included in the study. The collection of plasma samples was in the days following the hospital admission or the diagnosis of SARS-CoV-2 infection. For research purposes across studies, patients with COVID-19 were divided into three disease severity categories, defined according the clinical spectrum of SARS-CoV-2 infection covering mild, moderate and severe/critical illness as described in the latest guide of the National Institutes of Health COVID-19 treatment guidelines (www.covid19treatmentguidelines.nih.gov, accessed 11/25/2021). Mild grade is attributed to hospitalized patients who do not have respiratory symptoms or with mild symptoms to mild pneumonia and oxygen supplementation. Moderate grade is attributed to hospitalized patients with symptoms of bilateral pneumonia in need of high flow oxygen and respiratory distress in need of high flow oxygen, in some cases with the need of mechanical ventilation. Severe grade is attributed to hospitalized patients in critical care unit with mechanical ventilation and in some cases who die from COVID-19 disease. The degree of oxygen supplementation increases depending on the grade of the disease, even so the need for oxygen depended on the degree of hypoxia of each patient. On the other hand, a total of 69 plasma samples were collected from healthy blood donors before COVID-19 pandemic, having no COVID-19 disease, which were used as negative controls. Sera was stored at $-80^{\circ} \mathrm{C}$ until use. Mononuclear cells from healthy donors were purified 
after they had signed their informed consent agreement and whole peripheral blood samples were collected $(n=3)$.

\section{Reagents}

Different reagents and their sources used in this assay were: ultrapure Escherichia coli lipopolysaccharide (LPS) serotype 0111:B4 (InvivoGen), Adenosine 5'-triphosphate (ATP) was from Sigma-Aldrich and Clostridium difficile toxin B (TcdB) was from Enzo Life Sciences.

\section{PBMCs stimulation}

Human peripheral blood mononuclear cells were collected using Ficoll Histopaque1077 (Sigma-Aldrich) and cultured in Opti-MEM Reduced Serum Media (Invitrogen). PBMCs from patients were left unstimulated or stimulated with $1.6 \mu \mathrm{g} / \mathrm{ml}$ of LPS at 37 ${ }^{\circ} \mathrm{C}$ and then subsequently stimulated with ATP $5 \mathrm{mM}$ during $45 \mathrm{~min}$ or TcdB $1 \mu \mathrm{g} / \mathrm{ml}$ during $1 \mathrm{~h}$.

\section{ELISA}

Individual culture cell-free supernatants were collected and clarified by centrifugation. The concentration of human soluble P2X7 was tested by ELISA following the manufacturer's instructions (Cusabio). Plasma levels of human ASC, HMGB1, GSDMD and P2X7 were also tested by ELISA (Cusabio for ASC and P2X7, Aviva System Biology for GSDMD and Arigo Biolaboratories for HMGB1). Results were read in a Synergy Mx (BioTek) plate reader at $450 \mathrm{~nm}$ and corrected at $540 \mathrm{~nm}$.

\section{Multiplex}


Multiplexing in human serum for IL-15, IL-18, MCP-1, IL-2, IL-6 and IL-1RA was performed using the Luminex color-coded antibody-immobilized beads from Merck Millipore following the manufacture's indications, and the results were analysed in a Luminex MAGPIX instrument (Luminex Corporation).

\section{Statistics and data analysis}

Statistical analyses were performed using GraphPad Prism 9 (GraphPad Software Inc.). Normality of the samples was determined with D'Agostino and Pearson omnibus K2 normality test. Outliers from data sets were identified by the ROUT method with $Q=$ $1 \%$ and were eliminated from the analysis and representation. Non-parametric MannWhitney test was used to compare differences among two non-paired groups, and Kruskal-Wallis test was used to compare differences between three or more groups. The $x^{2}$-test was used to determine whether there was a significant difference between clinical variables among groups of patients. Non-parametric correlations were done according to Spearman correlation coefficient. All data are shown as mean values and errors bars represent standard error. 


\section{Competing interests}

LH-N, LM-A, DA-B, AB-M and PP are co-founders of Viva in vitro diagnostics SL, but declare that the research was conducted in the absence of any commercial or financial relationships that could be construed as a potential conflict of interest. The other authors declare no competing interests.

\section{Funding}

This work was supported by grants to PP from MCIN/AEI/10.13039/501100011033 (grant PID2020-116709RB-I00), Fundación Séneca (grants 20859/PI/18, 21081/PDC/19 and 0003/COVI/20) and European Research Council (grant ERC-2019PoC 899636). L.H-N. was supported by the fellowship 21214/FPI/19 (Fundación Séneca, Región de Murcia, Spain) and CM-L by was funded by the fellowship PRE2018-086824 (Ministerio economía y competitividad).

\section{Authors' Contributions}

JG-V, LH-N, AP-F and CM-L, experimental execution; JG-V, LH-N, and LM-A, sample collection; JG-V, LH-N, AP-F, CM-L, DA-B, AB-M and PP, data analysis; AB-M, DA-B and PP conceived the experiments; JG-V, LH-N and PP prepared the figures and wrote the paper; PP provided funding and overall supervision of the study.

\section{Acknowledgments}

We are particularly grateful for the generous contribution of the donors and the collaboration of Biobank Network of the Region of Murcia, BIOBANC-MUR, registered on the Registro Nacional de Biobancos with registration number B.0000859. BIOBANC-MUR is supported by the Instituto de Salud Carlos III (grant PT20/00109), by Instituto Murciano de Investigación Biosanitaria and by Consejeria de Salud de la Comunidad Autónoma de la Región de Murcia. We would like to thank all the members of Dr. Pelegrin's laboratory for comments and suggestions. 


\section{References}

1 Zhang, Q. et al. (2022) Human genetic and immunological determinants of critical COVID-19 pneumonia. Nature DOI: 10.1038/s41586-022-04447-0

2 Guo, Y.-R. et al. (2020) The origin, transmission and clinical therapies on coronavirus disease 2019 (COVID-19) outbreak - an update on the status. Mil. Med. Res. 7, 11

3 Abers, M.S. et al. (2021) An immune-based biomarker signature is associated with mortality in COVID-19 patients. JCI Insight 6,

4 Broz, P. et al. (2020) The gasdermins, a protein family executing cell death and inflammation. Nat. Rev. Immunol. 20, 143-157

5 Swanson, K. V. et al. (2019) The NLRP3 inflammasome: molecular activation and regulation to therapeutics. Nat. Rev. Immunol. 19, 477-489

6 Evavold, C.L. et al. (2018) The pore-forming protein gasdermin D regulates interleukin-1 secretion from living macrophages. Immunity 48, 35-44.e6

$7 \quad$ Xia, S. et al. (2021) Gasdermin D pore structure reveals preferential release of mature interleukin-1. Nature 593, 607-611

8 Di Virgilio, F. et al. (2017) The P2X7 Receptor in Infection and Inflammation. Immunity 47, 15-31

9 Christgen, S. et al. (2020) Toward targeting inflammasomes: insights into their regulation and activation. Cell Res. 30, 315-327

10 Pelegrin, P. (2021) P2X7 receptor and the NLRP3 inflammasome: Partners in crime. Biochem. Pharmacol. 187, 114385

11 Kroemer, A. et al. (2020) Inflammasome activation and pyroptosis in lymphopenic liver patients with COVID-19. J. Hepatol. 73, 1258-1262

12 Rodrigues, T.S. et al. (2021) Inflammasomes are activated in response to SARS-CoV-2 infection and are associated with COVID-19 severity in patients. J. Exp. Med. 218, e20201707

13 Junqueira, C. et al. (2021) SARS-CoV-2 infects blood monocytes to activate 
NLRP3 and AIM2 inflammasomes, pyroptosis and cytokine release. Res. Sq.

DOI: 10.21203/rs.3.rs-153628/v1

14 Kucia, M. et al. (2021) An evidence that SARS-Cov-2/COVID-19 spike protein (SP) damages hematopoietic stem/progenitor cells in the mechanism of pyroptosis in NIrp3 inflammasome-dependent manner. Leukemia DOI: $10.1038 / \mathrm{s} 41375-021-01332-z$

15 Vora, S.M. et al. (2021) Inflammasome activation at the crux of severe COVID19. Nat. Rev. Immunol. DOI: $10.1038 / s 41577-021-00588-x$

16 Amin, S. et al. (2021) NLRP3 inflammasome activation in COVID-19: an interlink between risk factors and disease severity. Microbes Infect. 110, 104913

17 Courjon, J. et al. (2021) Heterogeneous NLRP3 inflammasome signature in circulating myeloid cells as a biomarker of COVID-19 severity. Blood Adv. 5, $1523-1534$

18 Kyriazopoulou, E. et al. (2021) An open label trial of anakinra to prevent respiratory failure in covid-19. Elife 10, 1-21

$19 \mathrm{Xu}, \mathrm{H}$. et al. (2022) SARS-CoV-2 viroporin encoded by ORF3a triggers the NLRP3 inflammatory pathway. Virology 568, 13-22

20 Tapia-Abellan, A. et al. (2021) Sensing low intracellular potassium by NLRP3 results in a stable open structure that promotes inflammasome activation. Sci. Adv. in press,

21 Wu, X. et al. (2021) Secreted ORF8 is a pathogenic cause of severe Covid-19 and potentially targetable with select NLRP3 inhibitors. bioRxiv DOI:

$10.1101 / 2021.12 .02 .470978$

22 Pan, P. et al. (2021) SARS-CoV-2 N protein promotes NLRP3 inflammasome activation to induce hyperinflammation. Nat. Commun. 12, 4664

23 Theobald, S.J. et al. (2021) Long-lived macrophage reprogramming drives spike protein-mediated inflammasome activation in COVID-19. EMBO Mol. Med. DOI: $10.15252 / \mathrm{emmm} .202114150$ 
24 Yalcinkaya, M. et al. (2021) Modulation of the NLRP3 inflammasome by Sars-

CoV-2 Envelope protein. Sci. Rep. 11, 24432

25 Kim, N.-E. et al. (2021) SARS-CoV-2 Nonstructural Proteins 1 and 13 Suppress

Caspase-1 and the NLRP3 Inflammasome Activation. Microorganisms 9, 494

26 Ma, J. et al. (2021) SARS-CoV-2 nucleocapsid suppresses host pyroptosis by

blocking Gasdermin D cleavage. EMBO J. 40, 1-17

27 Giuliani, A.L. et al. (2019) The P2X7 Receptor Is Shed Into Circulation:

Correlation With C-Reactive Protein Levels. Front. Immunol. 10, 1-7

28 Rühl, S. et al. (2018) ESCRT-dependent membrane repair negatively regulates

pyroptosis downstream of GSDMD activation. Science 362, 956-960

29 Conte, G. et al. (2021) Circulating P2X7 Receptor Signaling Components as

Diagnostic Biomarkers for Temporal Lobe Epilepsy. Cells 10, 2444

30 Martínez-García, J.J. et al. (2019) P2X7 receptor induces mitochondrial failure in monocytes and compromises NLRP3 inflammasome activation during sepsis.

Nat. Commun. 10, 2711

31 Di Virgilio, F. et al. (2020) A rationale for targeting the P2X7 receptor in

Coronavirus disease 19. Br. J. Pharmacol. 177, 4990-4994

32 Ribeiro, D.E. et al. (2021) Hyperactivation of P2X7 receptors as a culprit of COVID-19 neuropathology. Mol. Psychiatry 26, 1044-1059

33 Cortegiani, A. et al. Rationale and evidence on the use of tocilizumab in COVID19: a systematic review. Pulmonology 27, 52-66

34 Dinarello, C.A. (1997) Interleukin-1. Cytokine Growth Factor Rev. 8, 253-65

35 Baroja-Mazo, A. et al. (2014) The NLRP3 inflammasome is released as a particulate danger signal that amplifies the inflammatory response. Nat. Immunol. 15, 738-748

36 Slaats, J. et al. (2016) IL-1ß/IL-6/CRP and IL-18/ferritin: Distinct Inflammatory Programs in Infections. PLoS Pathog. 12, 1-13

37 Holub, M. et al. (2013) Cytokines and chemokines as biomarkers of community- 
bioRxiv preprint doi: https://doi.org/10.1101/2022.03.04.483019; this version posted March 7, 2022. The copyright holder for this preprint (which was not certified by peer review) is the author/funder, who has granted bioRxiv a license to display the preprint in perpetuity. It is made available under aCC-BY-NC-ND 4.0 International license.

acquired bacterial infection. Mediators Inflamm. 2013, 190145 
bioRxiv preprint doi: https://doi.org/10.1101/2022.03.04.483019; this version posted March 7, 2022. The copyright holder for this preprint (which was not certified by peer review) is the author/funder, who has granted bioRxiv a license to display the preprint in perpetuity. It is made available under aCC-BY-NC-ND 4.0 International license.

Table 1. Demographic and clinical characteristics of the individuals included in this study

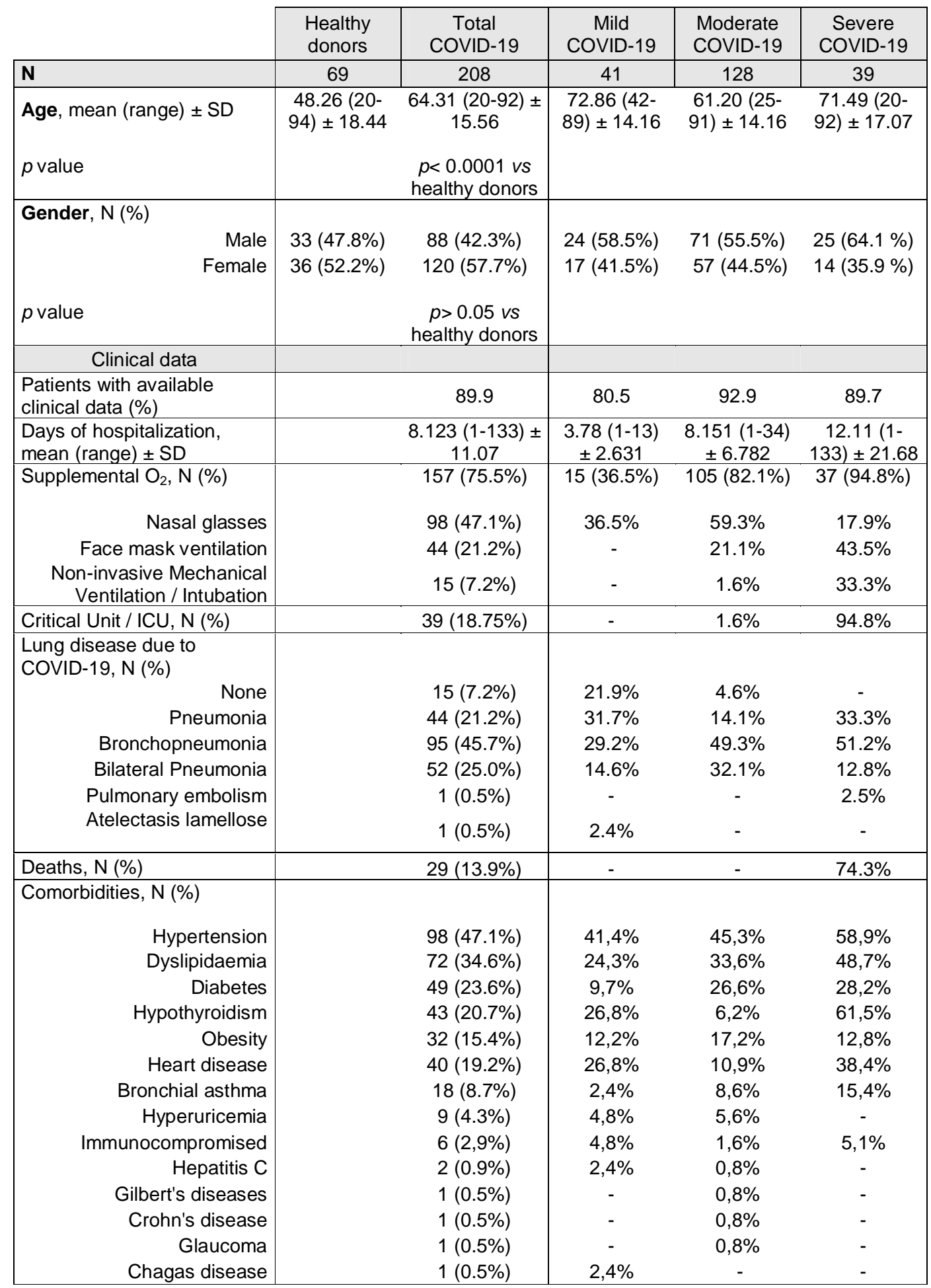




\section{Figure Legends}

Figure 1. Inflammatory cytokines and biomarkers are markedly induced in COVID-19 patients.

(A) Concentration of C-reactive protein (CRP), procalcitonin (PCT) and ferritin in plasma of COVID-19 patients.

(B-C) Plasma concentration of IL-6, IL-15, IL-1RA, IL18 (B), CCL2, and IL-2 (C) in healthy donors (HD) and COVID-19 patients.

(D) Plasma concentration of P2X7 receptor and markers of pyroptosis (ASC, GSDMD, and HMGB1) in healthy donors (HD) and COVID-19 patients.

Each dot represents an individual patient; data are represented as mean (grey bars) \pm s.e.m; dotted lines represent the normal range for each parameter analysed (upper line in Ferritin's graph correspond to normal range for healthy men and bottom line for healthy woman); For (B-D) ${ }^{* * *} p<0.0001$; ns, no significant difference $(p>0.05)$ with Mann-Whitney test.

Figure 2. P2X7 receptor and IL-1RA increase with COVID-19 disease severity.

(A) Plasma concentration of C-reactive protein (CRP), procalcitonin (PCT) and ferritin in association with the severity of COVID-19 manifestation (mild, moderate or severe). (B,C) Plasma concentration of P2X7 receptor, IL-1RA (B), IL-6, IL-15 and IL-18 (C) in plasma of healthy donors (HD) and COVID-19 patients in association with the severity of disease manifestation (mild, moderate or severe).

(D) Plasma concentration of P2X7 receptor in the plasma of HD and COVID-19 patients in different age groups.

Each dot represents an individual patient; data are represented as mean (grey bars) \pm s.e.m; dotted lines represent the normal range for each parameter analysed (upper line in Ferritin's graph correspond to normal range for healthy men and bottom line for healthy woman); ${ }^{* *} p<0.0021 ;{ }^{* *} p<0.0002 ;{ }^{* * * *} p<0.0001 ; n s$, no significant difference $(p>0.05)$ with Kruskal-Wallis test. 
Figure 3. P2X7 receptor detected in the plasma of COVID-19 patients correlates with C-reactive protein.

$(\mathrm{A}, \mathrm{B})$ Correlation between the concentration of C-reactive protein $(\mathrm{CRP})$ and the quantification of P2X7 receptor, IL-1RA (A), IL-6, IL-15 and IL-18 (B) in plasma from COVID-19 patients; disease severity is represented with yellow circles (mild), orange circles (moderate) and red circles (severe).

(C) Correlation between the concentration of CRP and the quantification of P2X7 receptor, IL-6 and IL-15 in plasma from COVID-19 patients in moderate (orange circles) and severe (red circles) COVID-19 manifestation.

(D) Correlation between the concentration of ferritin and CRP, P2X7 receptor, and IL18 in plasma from COVID-19 patients; disease severity is represented with yellow circles (mild), orange circles (moderate) and red circles (severe).

(E) Correlation between the concentration of P2X7 receptor and IL-1RA, IL-6, IL-15 and IL-18 from plasma of COVID-19 patients; disease severity is represented with yellow circles (mild), orange circles (moderate) and red circles (severe).

Each dot represents an individual patient; Pearson correlation for all panels.

Figure 4. Treatment with ATP or Clostridium difficile toxin B induces the release of $\mathrm{P} 2 \mathrm{X7}$ receptor.

Release P2X7 receptor (left) or IL-1 $\beta$ (right) from human peripheral blood mononuclear cells from healthy individuals treated for $3 \mathrm{~h}$ with LPS $(1.6 \mu \mathrm{g} / \mathrm{ml})$ and then treated with ATP $(5 \mathrm{mM})$ for $45 \mathrm{~min}$ or with Clostridium difficile toxin B (TcdB, $1 \mu \mathrm{g} / \mathrm{ml})$ for $1 \mathrm{~h}$. Each dot represents data from an independent individual. 

A

bioRxiv preprint doi: https://doi.org/10.1101/2022.03.04.483019; this version posted March 7, 2022. The copyright holder for this preprint (which was not certified by peer review) is the author/funder, who has granted bioRxiv a license to display the preprint in perpetuity. It is made available under aCC-BY-NC-ND 4.0 International license.
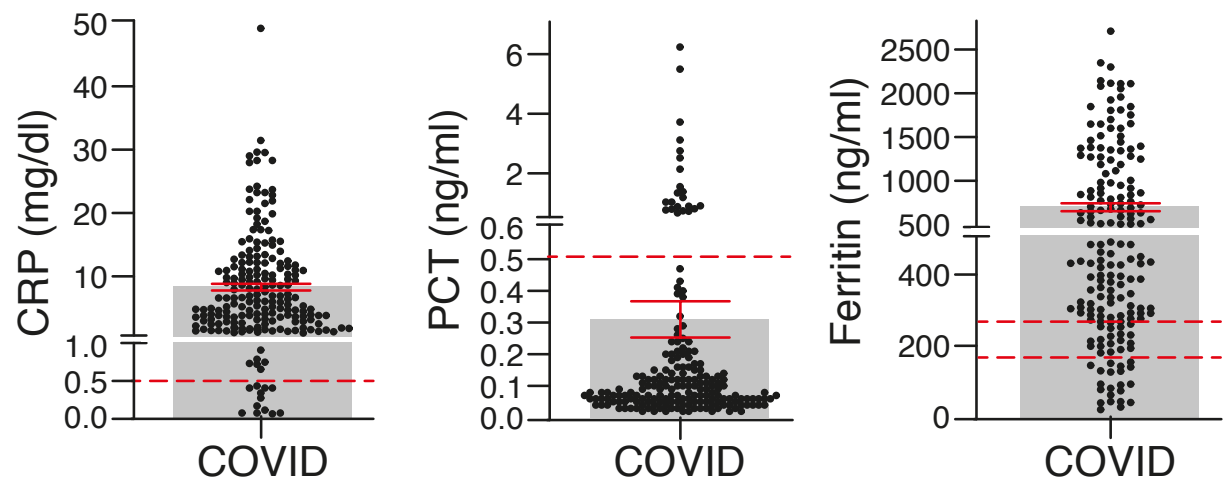

B

C
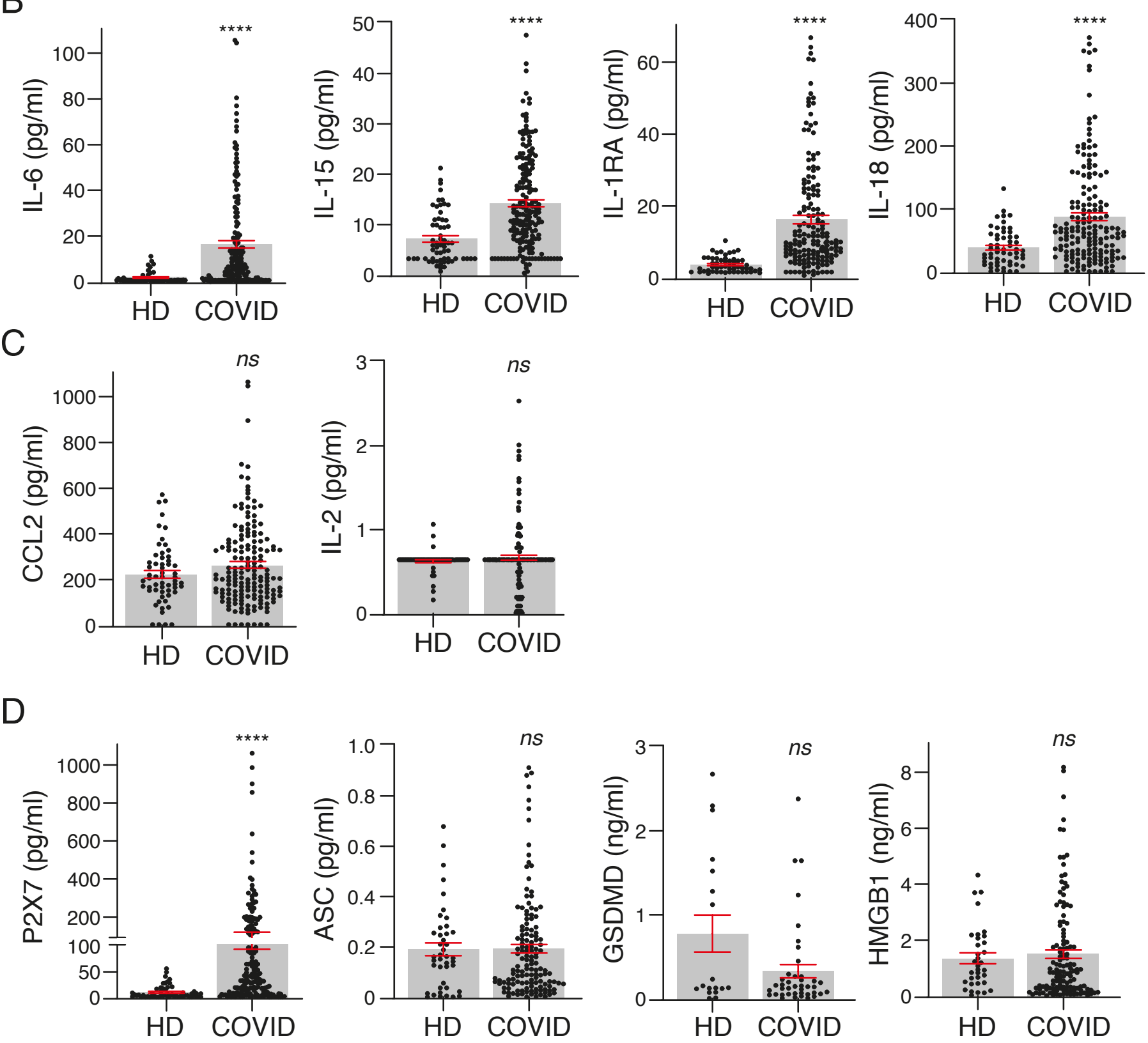
bioRAvv preprint doi: https://doi.org/10.1101/2022.03.04.483019; this version posted March 7, 2022. The copyright holder for this preprint (which was not certified by pee review), is the author/funder, who has*grated bioRxiv a license to display the preptint in perpetuity. It is made
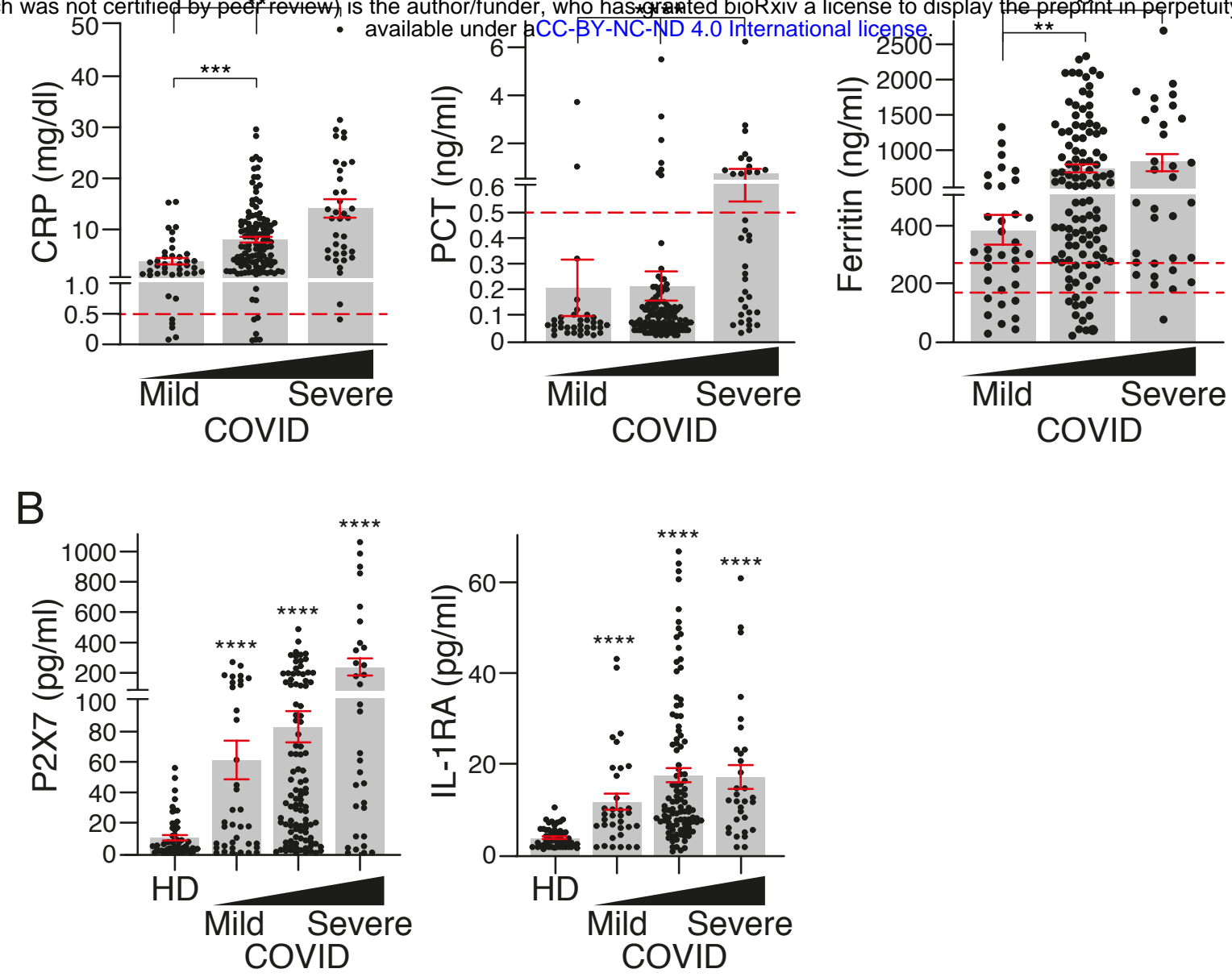

C
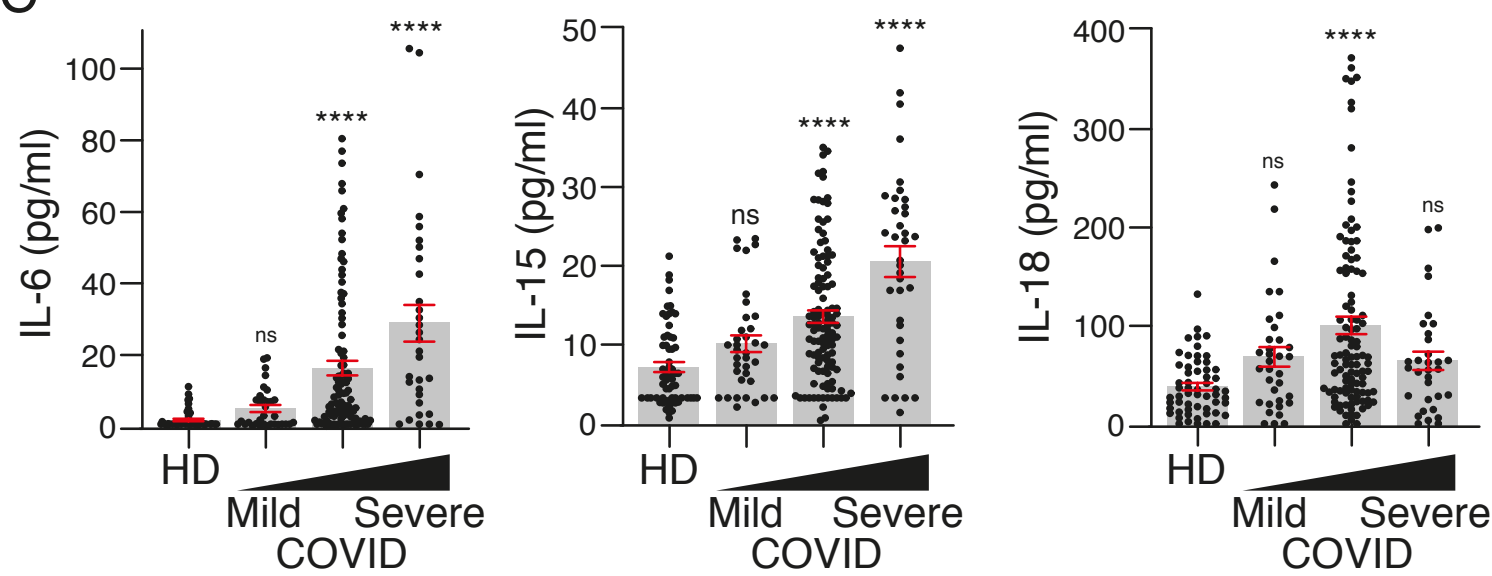

D

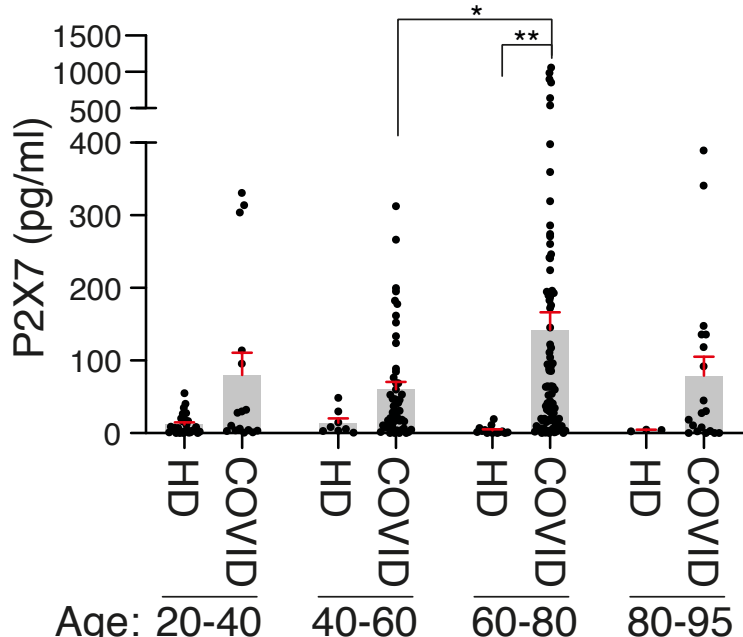


A
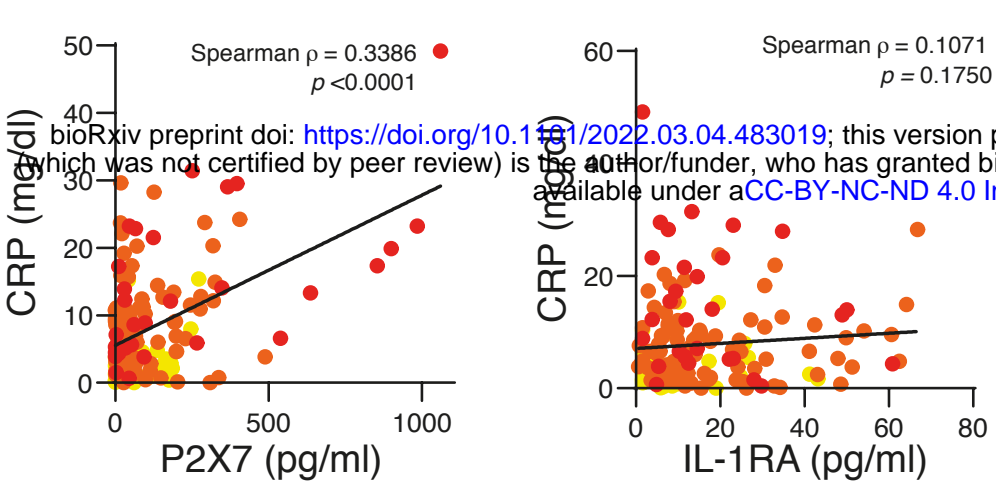

B
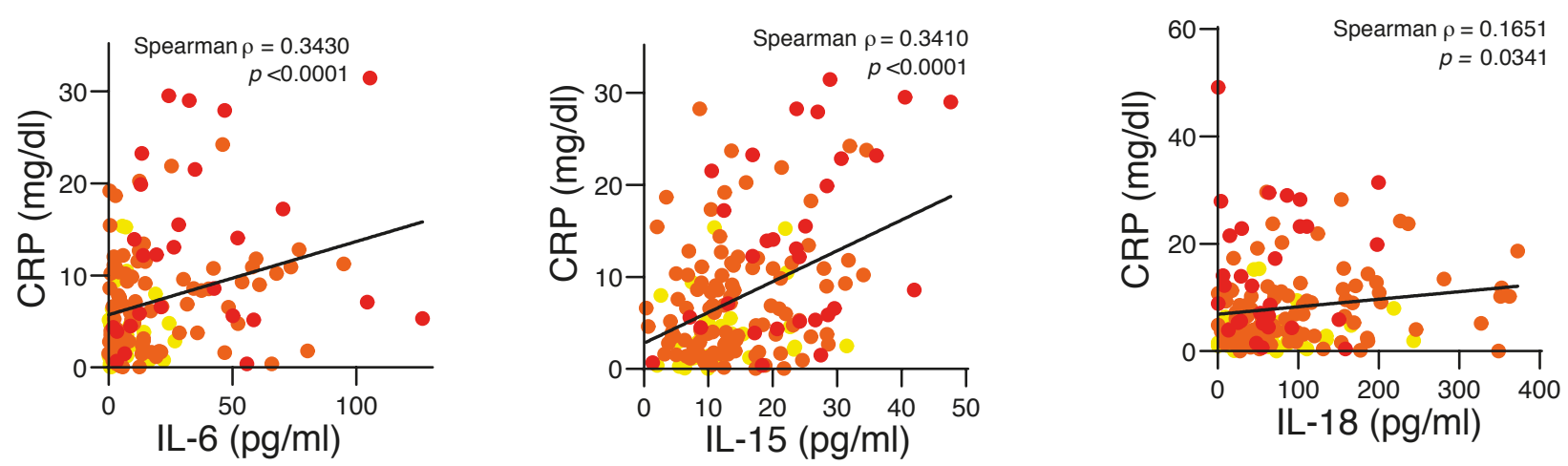

C
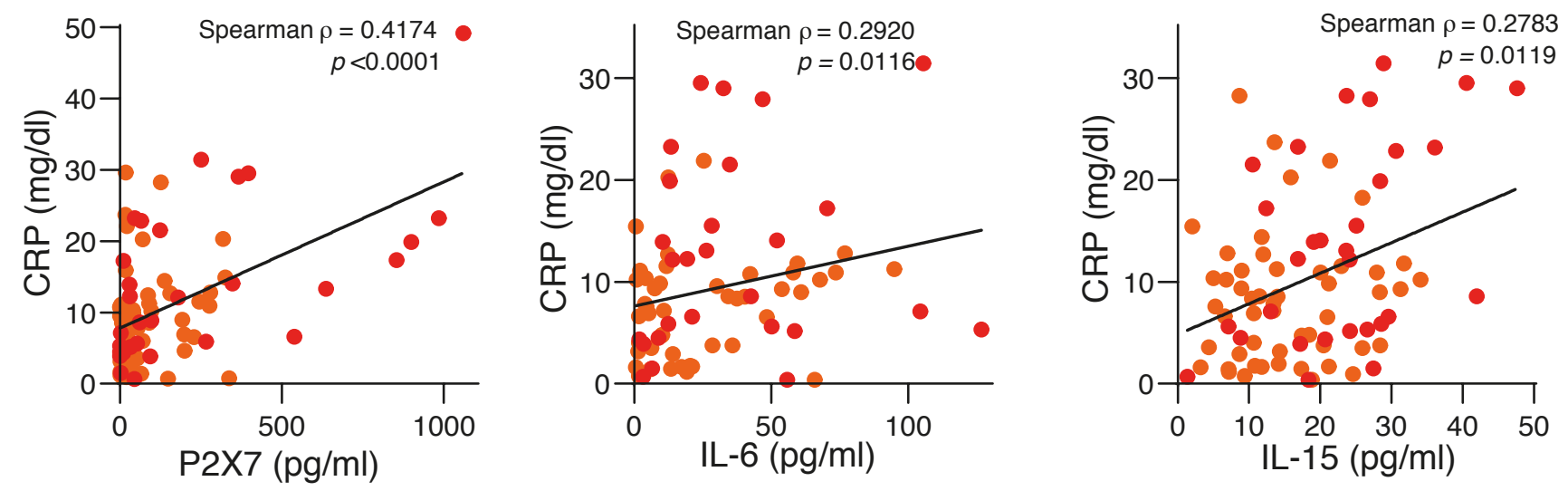

$\mathrm{D}$
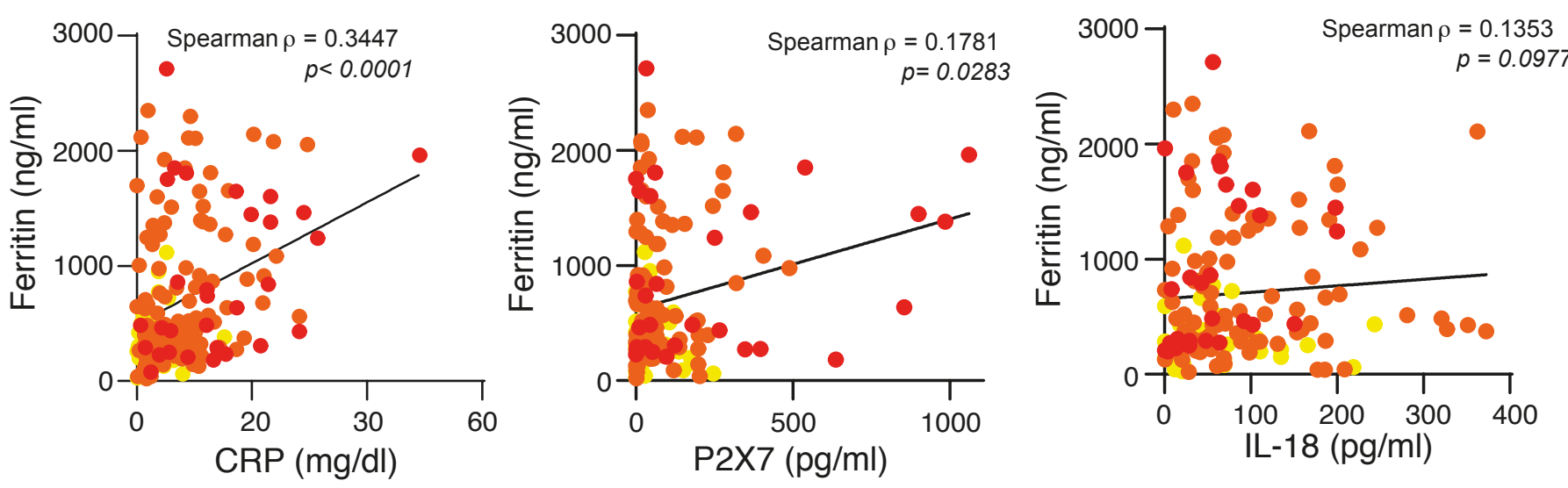

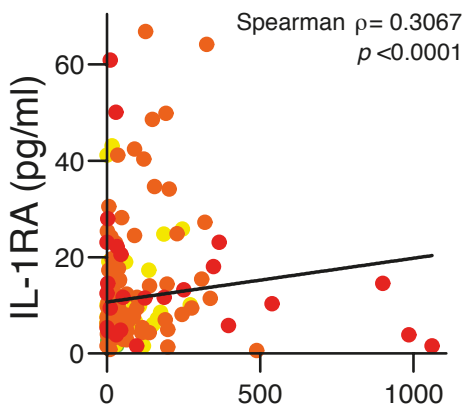

P2X7 (pg/ml)

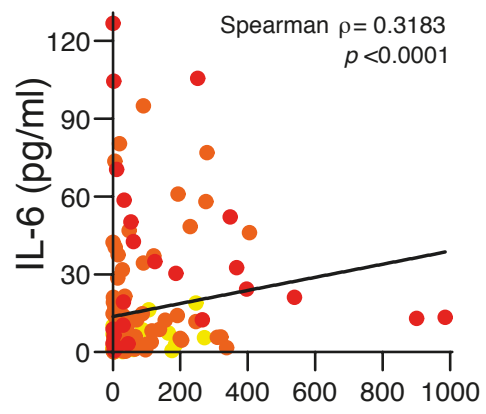

P2X7 (pg/ml)
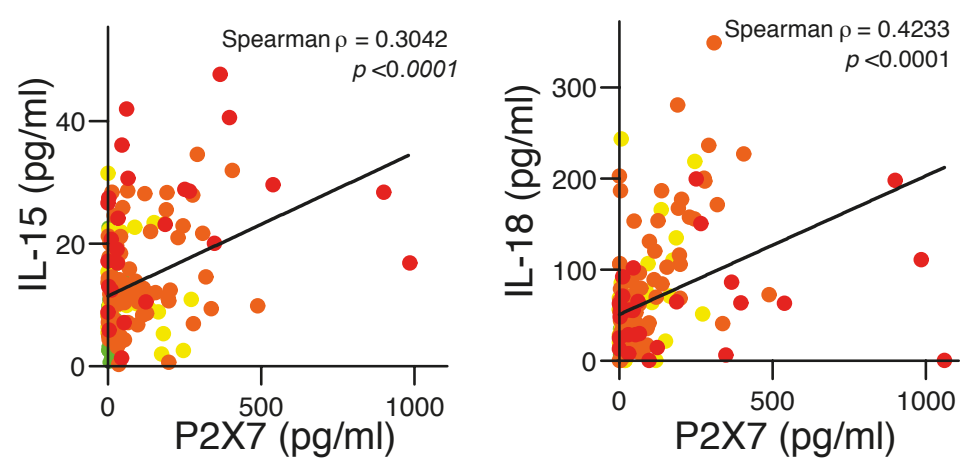

P2X7 (pg/ml) 
bioRxiv preprint doi: https://doi.org/10.1101/2022.03.04.483019; this version posted March 7, 2022. The copyright holder for this preprint (which was not certified by peer review) is the author/funder, who has granted bioRxiv a license to display the preprint in perpetuity. It is made available under aCC-BY-NC-ND 4.0 International license.
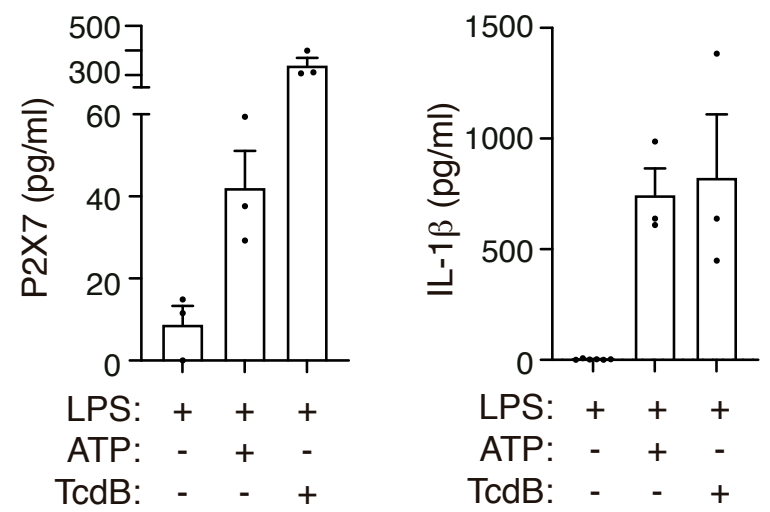